\title{
Effects Of Increasing The Involvement Of Community-Dwelling Frail Older Adults In A Proactive Assessment Service: A Pragmatic Trial
}

This article was published in the following Dove Press journal:

Clinical Interventions in Aging

\author{
W Rietkerk (D) \\ DL Gerritsen (iD ${ }^{2}$ \\ BJ Kollen' \\ CS Hofman (1D $)^{3}$ \\ K Wynia ${ }^{4, \dagger}$ \\ JPJ Slaets ${ }^{5,6}$ \\ SU Zuidema
}

'Department of General Practice and Elderly Care Medicine, University of

Groningen, University Medical Center Groningen, Groningen, the Netherlands; ${ }^{2}$ Department of Primary and Community Care and Radboud Alzheimer Centre, Radboud University Medical Center, Radboud Institute for Health Sciences, Nijmegen, the Netherlands; ${ }^{3}$ Department of Innovation and Research, Vilans, Centre of Expertise on Long-Term Care, Utrecht, the Netherlands; ${ }^{4}$ Department of Health Sciences, Community and Occupational Medicine, University of Groningen, University Medical Center Groningen, Groningen, the Netherlands; ${ }^{5}$ Faculty of Medical Sciences, University of Groningen, University Medical Centre Groningen, Groningen, the Netherlands; ${ }^{6}$ Leyden Academy On Vitality And Ageing, Leiden, the Netherlands

${ }^{\dagger} \mathrm{K}$ Wynia passed away on September 23, 2019
Background: Older adults and care professionals advocate a more integrated and proactive care approach. This can be achieved by proactive outpatient assessment services that offer comprehensive geriatric assessments to better understand the needs of older adults and deliver person-centered and preventive care. However, the effects of these services are inconsistent. Increased involvement of the older adult during the assessment service could increase the effects on older adult's well-being.

Methods: We studied the effect of an assessment service (Sage-atAge) for communitydwelling frail adults aged $\geq 65$ years. After studying the local experiences, this service was adapted with the aim to increase participant involvement through individual goal setting and using motivational interviewing techniques by health-care professionals (Sage-atAge+). Within Sage-atAge+, when finishing the assessment, a "goal card" was written together with the older adult: a summary of the assessment, including goals and recommendations We measured well-being with a composite endpoint consisting of health, psychological, quality of life, and social components. With regression analysis, we compared the effects of the Sage-atAge and Sage-atAge+ services on the well-being of participants.

Results: In total, 453 older adults were eligible for analysis with a mean age of $77( \pm 7.0)$ years of whom $62 \%$ were women. We found no significant difference in the change in wellbeing scores between the Sage-atAge+ service and the original Sage-atAge service (B, 0.037; $95 \% \mathrm{CI},-0.188$ to 0.263 ). Also, no change in well-being scores was found even when selecting only those participants for the Sage-atAge+ group who received a goal card.

Conclusion: Efforts to increase the involvement of older adults through motivational interviewing and goal setting showed no additional effect on well-being. Further research is needed to explore the relationship between increased participant involvement and wellbeing to further develop person-centered care for older adults.

Keywords: outpatient assessment service, well-being, comprehensive geriatric assessment, motivational interviewing, goal setting, person-centered care

\section{Introduction}

Multi-morbidity is common as people age, leading to increased dependency and frailty, ${ }^{1}$ with older adults often fearing progressive losses during this process. ${ }^{2}$ To prevent multi-morbidity, ${ }^{3}$ increase well-being, ${ }^{4}$ decrease care dependency, ${ }^{5}$ and deliver person-centered care, ${ }^{6}$ both older adults and care professionals advocate a more integrated and proactive approach. ${ }^{7,8}$ Therefore, proactive outpatient assessment services have been developed. They offer comprehensive geriatric assessments (CGAs) to
Correspondence: W Rietkerk

Department of General Practice and Elderly Care Medicine, University of Groningen, University Medical Cente Groningen, HPC FA2I, Postbus 196,

Groningen 9700 AD, the Netherlands Tel +31 651538759

Email w.rietkerk@umcg.nl 
better understand the needs of older adults and deliver person-centered and preventive care. ${ }^{9}$

CGAs are typically provided to at-risk populations based on criteria such as age, frailty, or certain morbidities. The assessment services may incorporate person-centered care, ${ }^{10}$ focusing on multiple domains, multidisciplinary care delivery, and individualized care plans. However, studies on the effects of assessment services from the last decade have produced inconsistent results. ${ }^{9}$ On the one hand, studies have shown that outpatient assessment services can decrease the number of hospital admissions ${ }^{11,12}$ and frailty. ${ }^{13,14}$ But on the other hand, they have been shown to have no effect on the quality of life. ${ }^{15,16}$ Both studies failing to find the effect on the quality of life used a randomized controlled trial (RCT) design and had little or no control over implementation of assessment recommendations.

Three reasons can be hypothesized for the lack of observing beneficial effects in earlier programs: the strict design, the role of the older adult, and the outcome measure. A proactive outpatient assessment service for frail community-dwelling older adults was developed, called Sage-atAge (in Dutch, Wijs Grijs), to tackle the issues of previous research.

First, a pragmatic design may be preferable to the mostly used RCT design. Sage-atAge has an pragmatic design that allowed for an easy adaption to the local situation and experiences of professionals and older adults involved. ${ }^{17}$ It is proposed as a preferable design to study the "real-world" effects of geriatric assessment programs. ${ }^{18}$

Second, a plausible and well-studied problem in the implementation of these programs is the poor adherence to recommendations of the geriatricians or geriatric teams and implementation of care plans. ${ }^{19,20}$ A way to improve this adherence is to increase the older adult involvement. ${ }^{21,22} \mathrm{In}$ Sage-atAge, older adult involvement is encouraged by motivational interviewing and goal setting. Motivational interviewing is a method to encourage people to make behavioral changes to improve health outcomes. ${ }^{23}$ It has been proven to be effective across different health-care settings for improving treatment adherence for chronic conditions. ${ }^{24}$ Goal setting is commonly seen as valuable in promoting the role of patients in decision-making and is an effective way to increase motivation in older adults. ${ }^{25}$ Goal setting proved feasible for older adults ${ }^{26}$ and suits the heterogeneous problems older adults with multi-morbidity face. ${ }^{27}$

The third reason for the observed lack of assessment programs may be due to the outcome measures used. ${ }^{28,29}$ Since these programs target heterogeneous problems experienced by frail older adults, a specific outcome measure such as function dependency may not be appropriate. In the present study, we used a composite endpoint (CEP) covering multiple (physiological, social, physical) domains that are associated with the different domains of well-being.

In this study, we evaluated both the Sage-atAge service and the potential benefit on general well-being of increasing older adult involvement by using motivational interviewing and goal setting. The evaluation had three objectives: (1) to improve our understanding of outpatient assessment services, (2) to determine why studies investigating these services produce inconsistent results, and (3) to further develop CGA in a person-centered way.

\section{Materials And Methods Design}

The Sage-atAge outpatient assessment service was offered by primary care practices (PCPs) to community-dwelling older adults aged $\geq 65$ years from a rural area in the northern part of the Netherlands, aiming to promote or preserve wellbeing. We evaluated the service on the effect of well-being within a pragmatic trial conducted between January 1, 2013, and April 30, 2017. First, we used a pragmatic design to adapt the service to local needs in close collaboration with care professionals (the Sage-atAge service). Second, the assessment process was adapted during the study when we identified a potential need to increase the involvement of older adults to enhance the service's impact (the Sage-atAge + service). The involvement of older adults in the SageatAge + service was promoted by motivational interviewing and goal setting. Third, we used a CEP that combined physical, psychological, and social well-being domains. Table 1 summarizes the components of the Sage-atAge and the Sage-atAge+ services.

\section{Intervention}

\section{The Sage-atAge service}

The basic Sage-atAge service consisted of two steps: (1) proactive screening of community-dwelling older adults for frailty and case complexity; and (2) assessment of needs by CGAs, with recommendations for the older adult and their general practitioner (GP).

\section{Screening}

All PCPs from three neighboring municipalities were invited to participate in the Sage-atAge service by e-mail, newsletter, and telephone. Seven PCPs (18\% of those approached) agreed to participate. The most 
Table I The Content Of The Sage-atAge And Sage-atAge+ Service

\begin{tabular}{|l|l|l|l|}
\hline Service Element & Content & Sage-atAge+ \\
\hline Start & Invitation by GP. & $\bullet$ \\
\hline Triage & Care profile (based upon frailty and case complexity) or frailty level. & $\bullet$ \\
\hline Assessment & $\begin{array}{l}\text { Multi-domain assessment by a nurse or elderly care physician. } \\
\text { Using motivational interviewing, setting goals, and filling in a goal card. } \\
\text { Oral screening by a dental care worker. } \\
\text { Medication evaluation by a pharmacist. } \\
\text { Additional: consult from an allied health-care professional. } \\
\text { Using motivational interviewing, setting goals, and adding these to the goal card. }\end{array}$ & $\bullet$ \\
\hline Actions & $\begin{array}{l}\text { Actions carried out by older adult and/or GP based on recommendations sent to the GP ... } \\
\ldots \text { and the goals and corresponding actions are written on the goal card and sent to the GP. }\end{array}$ & $\bullet$ \\
\hline
\end{tabular}

Abbreviation: GP, general practitioner.

prevalent reason for not participating was enrollment in another proactive screening service for older adults in the region. After obtaining consent from GPs, a postal questionnaire and informed consent form were sent to adults aged $\geq 65$ years in each PCP. GPs excluded patients with terminal illness or severe dementia.

Respondents were classified into four care profiles based on their self-reported level of frailty and complexity of care needs, as measured using the Groningen Frailty Indicator $(\mathrm{GFI})^{30}$ and INTERMED-E-SA, ${ }^{31}$ respectively. The care profiles were as follows: (1) feeling vital, (2) psychosocial coping difficulties, (3) physical and mobility needs, and (4) difficulties in multiple domains. ${ }^{32}$ These profiles were constructed in previous research by factor mixture model analysis and were used to adapt the service to patient needs. Older adults with a substantial frailty level (GFI $\geq 4)$ and/or a high care profile $(\geq 2)$ were invited for a CGA.

\section{Comprehensive Geriatric Assessments}

The CGA was provided by a nurse or an elderly care physician, with the latter reserved for the most complex and frail older adults (ie, care profile 4 ). ${ }^{33}$ The focus of these assessments was well-being, including social and functional participation, physical and psychological needs, and the living situation. A pharmacist also performed a risk assessment of drug-related problems based on the triage score system ${ }^{34}$ and the Structured HistoryTaking of Medication Use tool. ${ }^{35}$ Finally, a dental care worker took an oral history and assessed the oral cavity according to the Dutch Periodontal Screening Index). ${ }^{36}$ If consensus was reached between care professionals and participants, diagnostic consultations could be requested from dietitians, physiotherapists, psychologists, or occupational therapists. The problems identified, together with any recommendations, were communicated to the participant and his or her GP.

\section{The Sage-atAge+ Service}

Based on our interviews with participants, and supported by the experiences reported in other proactive assessment services, ${ }^{37}$ we identified that the involvement of older adults in the service needed to increase. Therefore, two components were added to meet this need: (1) goal setting and (2) motivational interviewing. These were developed jointly by researchers and the participating health-care professionals.

\section{Motivational Interviewing}

This is a method that can be used to encourage people to make behavioral changes to improve health outcomes. ${ }^{23}$ It was developed within psychiatry and has since been applied in diverse settings, including primary care, ${ }^{38,39}$ and has proven effectiveness at improving treatment adherence in chronic conditions. ${ }^{40,41}$ All involved healthcare professionals engaged in three 4-hr training sessions to increase their skill in the provision of motivational interviewing.

\section{Goal Setting}

This method is commonly used to increase patient involvement in decision-making and to increase their overall motivation. ${ }^{25}$ It has also been proven to be feasible for use with older adults ${ }^{26,42}$ in whom there are heterogeneous needs and multiple morbidities. ${ }^{27}$ To address goal setting, life and health-related goals were formulated with the 
direct input of the older adult. Written summaries of the assessment, consisting of one or more "points of concern," corresponding goals, and recommendations were formulated and written on a "goal card" with the input of the older adult, who was then asked to manage the implementation. The content of the goal card was recorded in the older adult's file and incorporated in the GP's letter.

To improve compliance and sustained adoption, two meetings were held for the participating health professionals during the first months after implementation to reinforce the use of goal cards and motivational interviewing.

\section{Sample}

Older adults assessed in the Sage-atAge service were included in the analyses if they provided written informed consent and data on their well-being at least once. Those enrolled from January 1, 2013 to August 31, 2014, were considered to have received the Sage-atAge service. Those enrolled from September 1, 2014, to April 30, 2016 (after the introduction of the goal card and the use of motivational interviewing) were considered to have received the Sage-atAge + service. Because of the pragmatic nature of the study, we used convenience sampling only.

\section{Measurement Instruments}

The participating older adults completed self-administered questionnaires at baseline and at 6-12 months after their assessments. Demographic data were collected about marital status, living situation, and educational level. Inclusion was then based on the frailty and case complexity of participants. Frailty was assessed using the GFI, which comprises 15 items that cover physical, social, cognitive, and psychological domains. The total score ranges from 0 to 15 , with a higher score indicating a higher level of frailty. ${ }^{30}$ Case complexity was measured with the INTERMED for the Elderly Self-Assessment. This assessment tool comprises 20 items divided into biological, psychological, social, and health-care domains by three perspectives: history, current state, and prognosis. The total score can range from 0 to 60 , with a higher score reflecting a higher complexity level. ${ }^{31}$

\section{Study Endpoint}

General well-being is a concept that covers a broad spectrum of health and it is influenced by various health outcome domains. ${ }^{43}$ Basically, these domains were covered within the Sage-atAge assessment. General well-being was assessed at baseline and at 6-12 months after CGA using an adapted version of the TOPICS-CEP score. ${ }^{43}$ This score was originally constructed with eight domains to operationalize general well-being and was considered appropriate for evaluating the effect of Sage-atAge. The TOPICS-CEP score produces a composite score, from eight clinical measures. It is a preference-weighted index ranging from 0 (worst possible state) to 10 (best possible state) that combines the data points from all domains. The preference weights of the TOPICS-CEP were derived from a vignette study among patients and caregivers. More detailed information about TOPICS-CEP, including a description of the data points, can be found elsewhere. ${ }^{43}$ The TOPICS-CEP score can identify different levels of frailty, and its constructs cover well-being. ${ }^{44}$ We omitted a domain for selfperceived health rating from the original TOPICS-CEP (a RAND-36 question on a 5-point Likert scale: How would you rate your current health state?). ${ }^{45}$ New regression analyses were performed and regression coefficients were retrieved from the original vignette dataset to adapt the TOPICS-CEP to the new TOPICS-CEP7 used in our questionnaire (see Table S1). The following variables were included in the TOPICS-CEP7:

- Dependency was measured using the modified Katz activities of daily living (ADL) index. This comprised 15 items (8 physical and 7 instrumental ADLs). The total score ranged from 0 to 1 . A higher score indicated a worse functional status. ${ }^{46}$

- Morbidity was measured by adding all diseases present from a list of chronic diseases (ie, dementia, depression, incontinence, stroke, hip fracture, panic or anxiety disorder, dizziness with falling, vision disorder, asthma, osteoporosis, diabetes, arthritis, heart failure, cancer, complaints due to benign enlarged prostate, fracture other than hip fracture, and hearing disorder). ${ }^{47}$

- Social functioning was assessed by a single item from the RAND-36 questionnaire (Are your social activities hampered by physical health or emotional problems?) on a 5-point Likert scale from never to continuously. ${ }^{45}$

- Psychological well-being was assessed by five questions from the mental health subscale of the RAND36 questionnaire (During the past 4 weeks, did you feel down, blue, nervous, happy, or calm?), which was rated on a 6-point Likert-type scale from always to never. The scores for the negative feelings (ie, blue, nervous, and down) were reversed. The sum of the five answers was calculated and the score could range from 5 to 30, with higher scores indicating lower psychological well-being. ${ }^{45}$ 
- Quality of Life was assessed by a rephrased question from the RAND-36 questionnaire (How satisfied are you with your quality of life?), which was rated on a 5-point Likert scale ${ }^{45}$ with scoring options ranging from excellent to poor.

- Pain and cognition were assessed by two items from the five EuroQol dimensions plus the cognition add on questionnaire (EQ-5D+C). Scoring options ranged from no pain to severe pain and from no cognitive problems to severe cognitive problems, both on 5point Likert scales. ${ }^{48,49}$

\section{Analyses}

All data were summarized using descriptive statistics. Categorical variables are described using frequencies and percentages. Continuous variables are described using means, SDs, and ranges, except for skewed variables, which are described by medians, interquartile ranges, and ranges. The level of significance was set at 0.05 for all statistical analyses, which were conducted using IBM SPSS Version 23 for Windows (IBM Corp., Armonk, NY, USA).

We tested for differences in frailty and case complexity between the included and excluded participants who provided data by independent $t$-tests. The difference in the TOPICSCEP7 was calculated between baseline and follow-up, and linear regression analysis was also applied to test the difference between the Sage-atAge and Sage-atAge+ groups at follow-up. Cases were excluded pairwise. In an adjusted model, propensity scores and TOPICS-CEP7 scores at baseline were included to reduce bias. ${ }^{50}$ The propensity score was developed by logistic regression based on demographic and care profile characteristics (eg, age, gender, educational level, living situation, frailty, and case complexity). We report the unstandardized (B) correlation coefficients with their $95 \%$ CIs for the unadjusted and adjusted regression models. Finally, to evaluate participants who received the Sage-atAge+ service as intended, a secondary subgroup analysis was performed by comparing the Sage-atAge group with the patients in the SageatAge+ group who received a goal card.

\section{Results}

\section{Participants}

In total, $48 \%$ of the older adults $(n=1455)$ completed the frailty and case complexity self-assessment and $21 \%(n=641)$ met the inclusion criteria and attended CGA (Figure 1). Of these, $29 \%(n=188)$ were excluded from analysis due to either a lack of informed consent $(n=154)$ or missing well-being data at both baseline and follow-up $(\mathrm{n}=34)$. Therefore, data for 453 participants were available for analysis. There were no significant differences in frailty or care complexity between the included older adults and those excluded because of missing data. The median period between assessment and followup was 8 months (interquartile range, 6-11).

The baseline characteristics of both groups were equivalent, as shown in Table 2. Overall, the mean age was 77 years (SD 7.0), 62\% were women, over half were married, onethird had a low educational level, and $96 \%$ were of Dutch ethnicity. Participants predominantly met the criteria for care profile 2 (51\%). The mean well-being score was 8.1 (SD 0.9) at baseline and ranged from 8.7 (SD 0.56 ) for care profile 1 to 6.7 (SD 1.1) for care profile 4. Elderly care physicians performed CGAs for $6 \%$ of the participants (Sage-atAge, $n$ $=13$; Sage-atAge,$+ \mathrm{n}=15$ ). The assessments by pharmacists and dental care assistants offered to all participants were attended by $93 \%$ (Sage-atAge, $n=203$; Sage-atAge+, $\mathrm{n}=217)$ and $47 \%$ (Sage-atAge, $\mathrm{n}=134$; Sage-atAge,$+ \mathrm{n}=$ 67), respectively. Additional consultations with other allied health-care professionals were attended by $18 \%$ (SageatAge, $n=25$; Sage-atAge,$+ n=57$ ).

\section{Outcomes}

\section{Well-Being}

There was no difference in the change in well-being score between the revised Sage-atAge + service and the regular Sage-atAge service in either the unadjusted or the adjusted analysis (Table 3, data for the total population). There were also no substantial differences between the baseline and follow-up data among the sub-variables of the TOPICS-CEP7. The within-group mean difference between well-being at baseline and follow-up for the Sage-atAge sample was 0.0 (SD 0.67) and for the SageatAge+ sample was 0.1 (SD 0.56).

\section{Goal Card Implementation}

In the Sage-atAge+ group, $53 \%(\mathrm{n}=121)$ of participants received a goal card. No change in the general well-being score was found even when selecting only these participants for the second group in the unadjusted and adjusted regression analyses (Table 3, data for participants who received a goal card).

\section{Discussion}

We found no additional benefit to the well-being of community-dwelling older adults when enriching a proactive assessment service with elements to increase their 


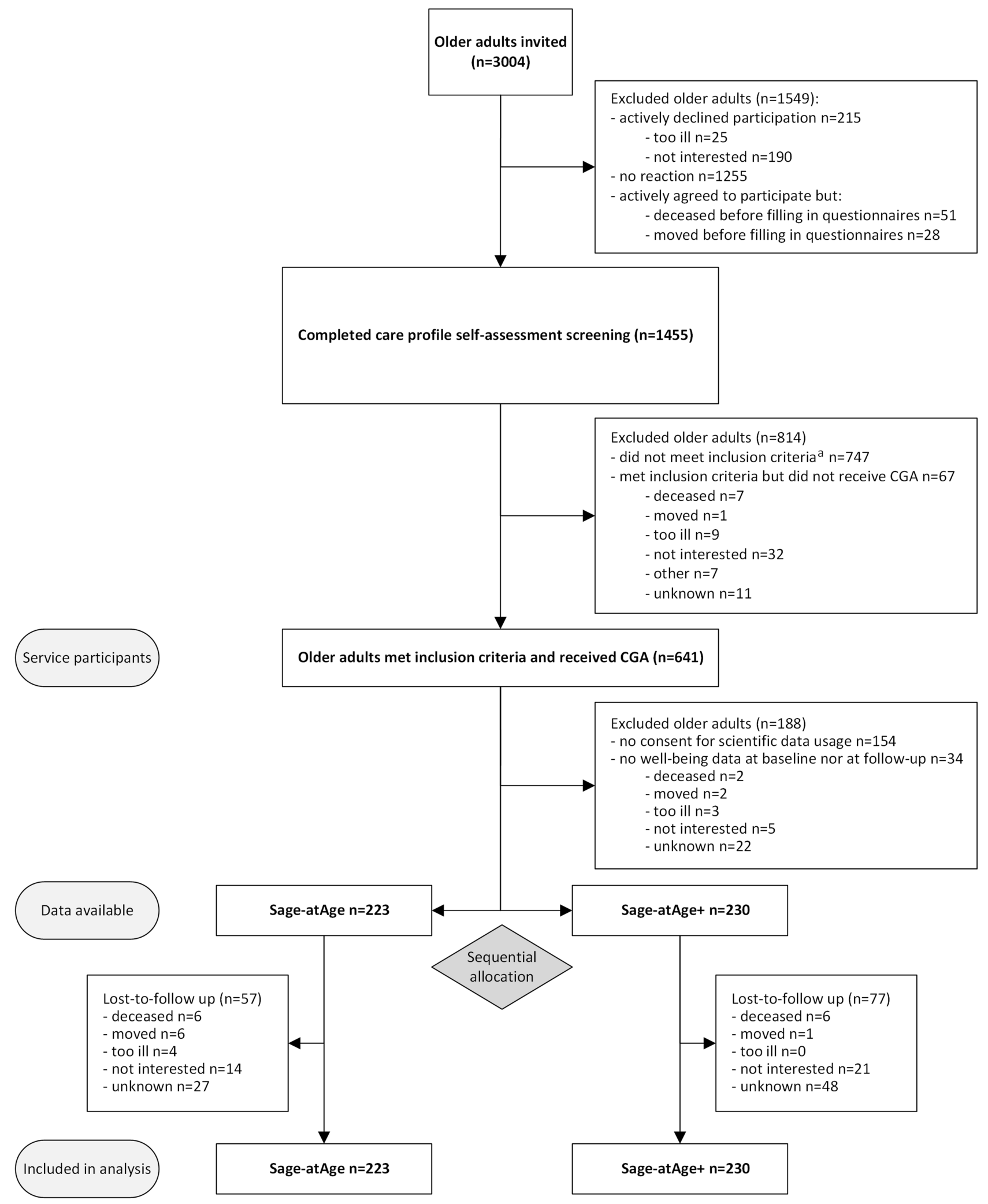

Figure I Flowchart of study participation.

Notes: ${ }^{a}$ Inclusion criteria: Groningen Frailty Indicator $\geq 4$ and/or a care profile $\geq 2$ Sage-atAge+ $=$ the Sage-atAge service with the additional aim of increasing the involvement of the older adult through motivational interviewing and goal setting.

involvement. This remained the case in a subgroup that received the additional service as intended. This adds to the mixed data surrounding the involvement of older adults in earlier studies. Similar to our result, no effect 
Table 2 Baseline Characteristics

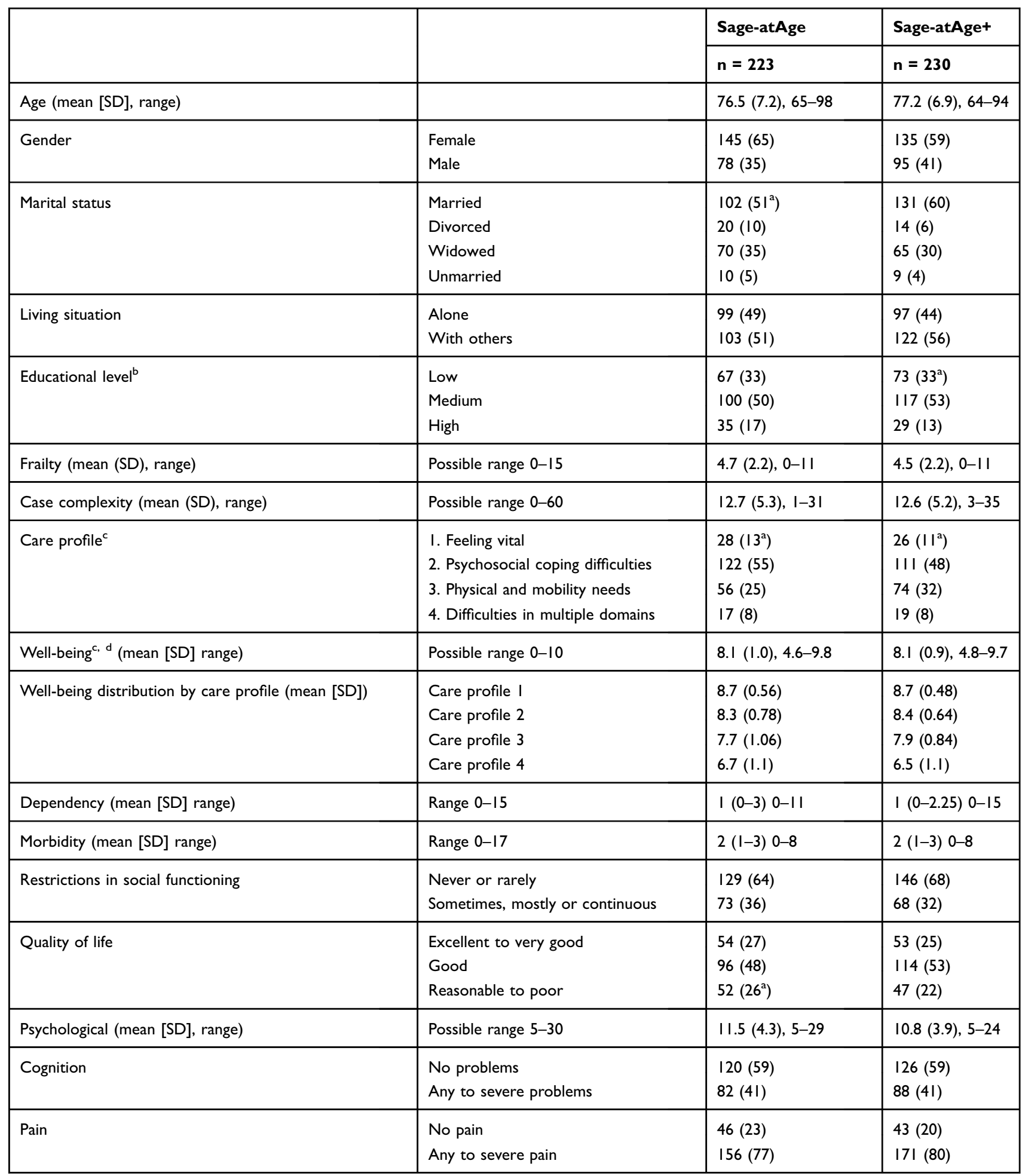

Notes: Values are numbers (percentages) unless stated otherwise. ${ }^{a}$ Sum $>100 \%$ or $<100 \%$ by rounding. ${ }^{b}$ Low $=$ preprimary school or low vocational training; medium $=$ secondary professional education; high $=$ higher professional education/university. ${ }^{\mathrm{C}} \mathrm{A}$ higher score indicates better performance. ${ }^{\mathrm{d}}$ Missing data $($ Sage-atAge, $n=21$; SageatAge+, $n=16$.

on patient outcomes was found in more extensive proactive services comprising case-management and focusing on promoting autonomy, ${ }^{29,51}$ or when using motivational interviewing. ${ }^{52}$ However, in other studies, positive effects have been shown on patient health or well-being following the implementation of goal setting ${ }^{53}$ and motivational 
Table 3 Linear Regression Models Of The Difference In General Well-Being Between The Two Service Options At Follow-Up

\begin{tabular}{|l|l|l|l|l|l|l|l|l|}
\hline & \multicolumn{2}{|l|}{ Unadjusted Model } & \multicolumn{3}{l|}{ Adjusted Model $^{\mathbf{a}}$} \\
\cline { 2 - 8 } & $\mathbf{B}$ & $\mathbf{9 5 \%} \mathbf{C l}$ & & $\mathbf{P}$ & $\mathbf{B}$ & $\mathbf{9 5 \%} \mathbf{C l}$ & $\mathbf{P}$ \\
\hline $\begin{array}{l}\text { Total population } \\
\text { Sage-atAge vs Sage-atAge+ }\end{array}$ & 0.037 & -0.188 & 0.263 & 0.75 & 0.029 & -0.118 & 0.177 & 0.70 \\
\hline Participants who received the service as intended & & & & & \\
\hline Sage-atAge vs Sage-atAge+ & 0.193 & -0.065 & 0.452 & 0.14 & 0.063 & -0.111 & 0.238 & 0.48 \\
\hline
\end{tabular}

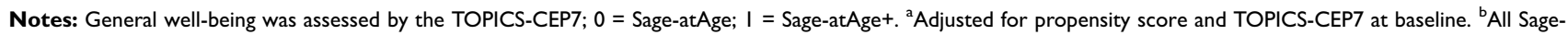
atAge participants and the selection of Sage-atAge+ participants receiving a goal card.

interviewing. ${ }^{41,54}$ These mixed results can be explained by at least two factors. First, interventions are more effective when they address homogeneous populations, such as patients with a single chronic condition, because it is easier for care professionals to adapt to a smaller scope of problems and interventions. Second, the studies with positive outcomes used more intensive strategies with more behavior change techniques, including goal planning, an active follow-up strategy, specific goal requirements, or protocol-based interventions to act upon goals, whereas we only implemented goal setting. ${ }^{55}$

We used a pragmatic design to examine the impact of multicomponent services. However, this approach has disadvantages compared to RCT designs. An advantage of the RCT design is that differences between two groups are minimized by randomization. Even though we used sequential allocation instead of randomization, there was no difference in any domain measured between samples at baseline. This is reflected in a mean propensity score of 0.51 (SD 0.1) for the Sage-atAge group and 0.53 (SD 0.1) for the Sage-atAge+ group. A propensity score of 0.5 (SD $0.0)$ would indicate no difference between the groups. ${ }^{56}$ Despite this disadvantage, the pragmatic design has two advantages over the RCT design, namely the broader inclusion criteria and the flexibility of intervention application, ${ }^{57}$ and these are discussed next.

First, the inclusion criteria for pragmatic trials are typically less selective than the strict criteria used in RCTs, which aim to achieve a homogeneous group to test the efficacy of an intervention protocol. In this study, we only excluded older adults in care profile 1 and those with severe dementia or a terminal illness from the SageatAge service to ensure that a large heterogeneous group could benefit from a service, thereby increasing the generalizability of the study outcome. Second, the intervention flexibility permitted by the pragmatic design provided an opportunity to bridge the gap between scientific knowledge about increasing patient involvement and practical applicability in daily practice. This is highly encouraged for CGA practice. Although there is good evidence in support of CGA use, only limited data exist about its implementation in routine practice across different health-care settings. ${ }^{18}$ When assessing CGA programs by RCTs, it has been stated that developers failed to study local settings beforehand, so could not adapt to the requirements of those settings. ${ }^{37}$ Bridging this so-called know-do gap requires moving away from restrictive RCT designs. In the Sage-atAge+ service, we adjusted the assessment approach based on participant experience during service delivery. This collaboration between research and care professionals can help overcome several barriers to implementation. ${ }^{58}$ For example, it is expected to lead to better adaptation to the field, greater adoption by care professionals, and a higher likelihood of intervention sustainability. To study whether these expectations are true for the Sage-atAge+ service, we have gathered important process data from daily practice and can now perform a thorough process evaluation focusing on the effect of increased involvement by older adults.

It is worth considering the possibility of imperfect implementation of the two intervention components. Half of the older adults received a goal card to support goal attainment, yet the utility of these cards was not known. Additionally, goal setting can be hampered by unrealistic goals or a lack of familiarity with giving and receiving this method of care. ${ }^{59}$ The implementation of motivational interviewing may also be limited by the skills and engagement of care professionals. Indeed, motivational interviewing is often taught over short training periods (eg, $\leq 12$ $\mathrm{hrs})^{60}$ and it is questionable whether this is sufficient to provide the skill and spirit needed to execute it effectively. ${ }^{61}$ Treatment fidelity should be evaluated by a 
thorough process analysis exploring these possible limitations. In addition to these debates, implementation of goal setting could be more intensified by adding goal planning and other behavioral change techniques to increase the impact of the service. ${ }^{55}$

Some remarks should also be made about the outcome measure. There were no differences in well-being over time in any group or sub-variable, but as shown in Table 2, the TOPICS-CEP7 could discriminate between differences in frailty and case complexity. It is therefore possible that the 1-year follow-up period was too short to detect changes in well-being and health-related patientreported outcome measures. Due to the one-off nature of the service, we preferred a maximum follow-up period of 1 year to allow well-being to change due to goal progress, but to decrease the detection of changes caused by something else than the service, for example, changes associated with aging.

To improve the patient-centeredness of care with such a service, it may be better to measure quality of care ${ }^{62}$ and the autonomy, as experienced and preferred by patients during care. Finally, the fact that we adapted the original TOPICS-CEP by excluding the self-perceived health component was likely trivial to the outcome given that all other components showed only minor changes.

\section{Conclusion}

Efforts to increase the engagement of older adults in a proactive assessment service by using motivational interviewing and goal setting produced no additional benefits to well-being. This lack of change could be explained by poor implementation in the current setting, but given that we used a pragmatic design that facilitates implementation, we do not anticipate that results will improve in other settings. Therefore, we recommend that future efforts focus on changing the intervention itself. First, to increase program embedding within existing care, future provision should ensure that stakeholders (eg, older adults and GPs) are involved in service development and understand its goals. In this way, knowledge translation can occur from science to practice while concurrently adapting the research design to local needs. ${ }^{17,18}$ Second, interventions that are more intensive should be developed by adding other behavior change techniques, such as goal planning, to improve the involvement of older adults in their own care. Third, outcome measures should become more patient-centered through the use of either individual goals or goal setting instruments.

\section{Ethics Approval And Informed Consent}

An appropriate ethics committee confirmed that the study did not require ethical approval \{blinded for peer review\}. The study was conducted in accordance with the Declaration of Helsinki and the Code of Conduct for Health Research (2004) as well as all applicable regulations in the Netherlands. Written informed consent was obtained from older adults before participating in the study.

\section{Abbreviations}

ADL, activities of daily living; CEP, composite endpoint; CGA, comprehensive geriatric assessments; GFI, Groningen Frailty Indicator; GP, general practitioner; PCP, primary care practices; RCT, randomized controlled trial.

\section{Data Availability}

Data are available upon reasonable request to the first author.

\section{Acknowledgment}

We thank Dr Robert Sykes for providing editorial services.

\section{Funding}

This work was supported by the Innovation Fund of Friesland Care Insurance (In Dutch: Innovatiefonds De Friesland Zorgverzekeraar), Leeuwarden, the Netherlands (0710-14599/DS44). The funding body played no role in the design of the study, the interpretation of the data, or the decision to publish the article.

\section{Disclosure}

The authors report no conflicts of interest in this work.

\section{References}

1. Marengoni A, Angleman S, Melis R, et al. Aging with multimorbidity: a systematic review of the literature. Ageing Res Rev. 2011;10(4):430439. doi:10.1016/j.arr.2011.03.003

2. Spoorenberg SLW, Wynia K, Fokkens AS, Slotman K, Kremer HPH, Reijneveld SA. Experiences of community-living older adults receiving integrated care based on the chronic care model: a qualitative study. PLoS One. 2015;10(10):e0137803. doi:10.1371/journal. pone. 0137803

3. Dowrick C. Patient-centred care for multimorbidity: an end in itself? Lancet. 2018;392(10141):4-5. doi:10.1016/S0140-6736(18)31386-2

4. Hopman P, de Bruin SR, Forjaz MJ, et al. Effectiveness of comprehensive care programs for patients with multiple chronic conditions or frailty: a systematic literature review. Health Policy (New York). 2016;120(7):818-832. doi:10.1016/j.healthpol.2016.04.002

5. World Report on Ageing and Health. Geneva: World Health Organization; 2015. doi:10.1007/s13398-014-0173-7.2 
6. D’Avanzo B, Shaw R, Riva S, et al. Stakeholders' views and experiences of care and interventions for addressing frailty and pre-frailty: a meta-synthesis of qualitative evidence. Virgili G, ed. PLoS One. 2017;12(7):e0180127. doi:10.1371/journal.pone.0180127

7. Greenfield G, Ignatowicz AM, Belsi A, et al. Wake up, wake up! It's me! It's my life! patient narratives on person-centeredness in the integrated care context: a qualitative study. BMC Health Serv Res. 2014;14:619. doi:10.1186/s12913-014-0619-9

8. Vestjens L, Cramm JM, Nieboer AP. An integrated primary care approach for frail community-dwelling older persons: a step forward in improving the quality of care. BMC Health Serv Res. 2018;18 (1):1-13. doi:10.1186/s12913-017-2827-6

9. Pilotto A, Cella A, Pilotto A, et al. Three decades of comprehensive geriatric assessment: evidence coming from different healthcare settings and specific clinical conditions. J Am Med Dir Assoc. 2016;18 (2):192.e1-192.e11. doi:10.1016/j.jamda.2016.11.004

10. Global strategy on people-centred and integrated health services interim report. Geneva: World Health Organization; 2015. Available from: http://www.who.int/servicedeliverysafety/areas/people-centredcare/global-strategy/en/. Accessed November 1, 2019.

11. Fenton JJ, Levine MD, Mahoney LD, Heagerty PJ, Wagner EH. Bringing geriatricians to the front lines: evaluation of a quality improvement intervention in primary care. J Am Board Fam Med. 2006;19(4):331-339. doi:10.3122/jabfm.19.4.331

12. Clarkson P, Brand C, Hughes J, Challis D. Integrating assessments of older people: examining evidence and impact from a randomised controlled trial. Age Ageing. 2011;40(3):388-408. doi:10.1093/ageing/afr015

13. Cameron ID, Fairhall N, Langron C, et al. A multifactorial interdisciplinary intervention reduces frailty in older people: randomized trial. BMC Med. 2013;11(1):65. doi:10.1186/1741-7015-11-65

14. Mazya AL, Garvin P, Ekdahl AW Outpatient comprehensive geriatric assessment: effects on frailty and mortality in old people with multimorbidity and high health care utilization. Aging Clinical and Experimental Research. [Published July 23, 2018]. Available from: http://www.ncbi. nlm.nih.gov/pubmed/30039453. Accessed July 30, 2018.

15. Ekdahl AW, Wirehn AB, Alwin J, et al. Costs and effects of an ambulatory geriatric unit (the AGe-FIT Study): a randomized controlled trial. J Am Med Dir Assoc. 2015;16(6):497-503. doi:10.1016/ j.jamda.2015.01.074

16. Parsons M, Senior H, Mei-Hu Chen X, et al. Assessment without action; a randomised evaluation of the inter RAI home care compared to a national assessment tool on identification of needs and service provision for older people in New Zealand. Health Soc Care Community. 2013;21(5):536-544. doi:10.1111/hsc.12045

17. Vandenbroucke JP. Observational research, randomised trials, and two views of medical science. PLoS Med. 2008;5(3):0339-0343. doi:10.1371/journal.pmed.0050067

18. Gladman JRF, Conroy SP, Ranhoff AH, Gordon AL. New horizons in the implementation and research of comprehensive geriatric assessment: knowing, doing and the "know-do" gap. Age Ageing. 2016;45 (2):194-200. doi:10.1093/ageing/afw012

19. Aminzadeh F. Adherence to recommendations of community-based comprehensive geriatric assessment programmes. Age Ageing. 2000;29(5):401-407. doi:10.1093/ageing/30.2.177

20. Chen P, Steinman MA. Perception of primary care physicians on the impact of comprehensive geriatric assessment: what is the next step? Isr $J$ Health Policy Res. 2016;5(1):3-6. doi:10.1186/s13584-016-0106-3

21. Maly RC, Leake B, Frank JC, DiMatteo MR, Reuben DB. Implementation of consultative geriatric recommendations: the role of patient-primary care physician concordance. J Am Geriatr Soc. 2002;50(8):1372-1380. doi:10.1046/j.1532-5415.2002.50358.x

22. Larsson IE, Sahlsten MJ, Sjostrom B, Lindencrona CS, Plos KA. Patient participation in nursing care from a patient perspective: a grounded theory study. Scand J Caring Sci. 2007;21(3):313-320. doi:10.1111/j.1471-6712.2007.00471.x
23. Rollnick S, Miller WR. What is motivational interviewing? Behav Cogn Psychother. 1995;23(4):325-334. doi:10.1017/S135246580001643X

24. Lundahl B, Burke BL. The effectiveness and applicability of motivational interviewing: a practice-friendly review of four meta-analyses. J Clin Psych Sess. 2009;65(11):1232-1245. doi:10.1002/jclp

25. Powell J, Bray J, Roberts H, Goddard A, Smith E. Goal negotiation with older people in three day care settings. Health Soc Care Community. 2000;8(6):380-389. doi:10.1046/j.1365-2524.2000.00263.x

26. Toto PE, Skidmore ER, Terhorst L, Rosen J, Weiner DK. Goal Attainment Scaling (GAS) in geriatric primary care: A feasibility study. Arch Gerontol Geriatr. 2015;60(1):16-21. doi:10.1016/j. archger.2014.10.022

27. Robben SHM, Perry M, Olde Rikkert MGM, Heinen MM, Melis RJF. Care-related goals of community-dwelling frail older adults. J Am Geriatr Soc. 2011;59(8):1552-1554. doi:10.1111/j.1532-5415.2011.03515.x

28. Ruikes FGH, Zuidema SU, Akkermans RP, Assendelft WJJ, Schers HJ, Koopmans RTCM. Multicomponent program to reduce functional decline in frail elderly people: a cluster controlled trial. J Am Board Fam Med. 2016;29(2):209-217. doi:10.3122/jabfm.2016.02.150214

29. Spoorenberg SLW, Wynia K, Uittenbroek RJ, Kremer HPH, Reijneveld SA. Effects of a population-based, person-centred and integrated care service on health, wellbeing and self-management of community-living older adults: a randomised controlled trial on Embrace. PLoS One. 2018;13(1):2-10. doi:10.1371/journal. pone.0190751

30. Peters LL, Boter H, Buskens E, Slaets JPJ. Measurement properties of the Groningen Frailty Indicator in home-dwelling and institutionalized elderly people. J Am Med Dir Assoc. 2012;13(6):546-551. doi:10.1016/j.jamda.2012.04.007

31. Peters LL, Boter H, Slaets JPJ, Buskens E. Development and measurement properties of the self assessment version of the INTERMED for the elderly to assess case complexity. J Psychosom Res. 2013;74(6):518-522. doi:10.1016/j.jpsychores.2013.02.003

32. Eissens van der Laan MR, van Offenbeek MG, Broekhuis H, Slaets JPJ. A person-centred segmentation study in elderly care: towards efficient demand-driven care. Soc Sci Med. 2014;113:68-76. doi:10.1016/j.socscimed.2014.05.012

33. Koopmans RTCM, Pellegrom M, van der Geer ER. The Dutch move beyond the concept of nursing home physician specialists. J Am Med Dir Assoc. 2017;18(9):746-749. doi:10.1016/j.jamda.2017.05.013

34. Van Roon EN, Van Asselt DZB, Vogel D, Van Dijk N, Brouwers RBJ. Risk assessment for clinical pharmacists to detect drug related problems in geriatric patients: results of validation of an easy-to-use triage score system. Basic Clin Pharmacol Toxicol. 2007;101(Suppl. 1):191-192.

35. Drenth-Van Maanen AC, Spee J, Van Marum RJ, Egberts TCG. Structured history taking of medication use reveals iatrogenic harm due to discrepancies in medication histories in hospital and pharmacy records. J Am Geriatr Soc. 2011;59(10):1976-1977. doi:10.1111/ j.1532-5415.2011.03610_11.x

36. Van Der Velden U. The Dutch periodontal screening index validation and its application in the Netherlands. J Clin Periodontol. 2009;36 (12):1018-1024. doi:10.1111/j.1600-051X.2009.01495.x

37. Smit LC, Schuurmans MJ, Blom JW, et al. Unravelling complex primary-care programs to maintain independent living in older people: a systematic overview. J Clin Epidemiol. 2018;96:110-119. doi:10.1016/j.jclinepi.2017.12.013

38. Noordman J, De Vet E, Van der Weijden T, Van Dulmen S. Motivational interviewing within the different stages of change: an analysis of practice nurse-patient consultations aimed at promoting a healthier lifestyle. Soc Sci Med. 2013;87:60-67. doi:10.1016/j. socscimed.2013.03.019

39. Morton K, Beauchamp M, Prothero A, et al. The effectiveness of motivational interviewing for health behaviour change in primary care settings: a systematic review. Health Psychol Rev. 2015;9 (2):205-223. doi:10.1080/17437199.2014.882006 
40. Lundahl B, Moleni T, Burke BL, et al. Motivational interviewing in medical care settings: a systematic review and meta-analysis of randomized controlled trials. Patient Educ Couns. 2013;93(2):157168. doi:10.1016/j.pec.2013.07.012

41. Moral RR, de Torres LAP, Ortega LP, et al. Effectiveness of motivational interviewing to improve therapeutic adherence in patients over 65 years old with chronic diseases: a cluster randomized clinical trial in primary care. Patient Educ Couns. 2015;98(8):977-983. doi:10.1016/j.pec.2015.03.008

42. Robben SHM, Heinen MM, Perry M, et al. First experiences with a two-step method for discussing goals with community-dwelling frail older people. Heal Expect. 2015;18(5):1559-1566. doi:10.1111/ hex. 12145

43. Hofman CS, Makai P, Boter H, et al. Establishing a composite endpoint for measuring the effectiveness of geriatric interventions based on older persons' and informal caregivers' preference weights: a vignette study. BMC Geriatr. 2014;14(1). doi:10.1186/1471-231814-51

44. Hofman CS, Lutomski JE, Boter H, et al. Examining the construct and known-group validity of a composite endpoint for the Older Persons and Informal Caregivers Survey Minimum Data Set (TOPICS-MDS); A largescale data sharing initiative. PLoS One. 2017;12(3):1-12. doi:10.1371/journal.pone.0173081

45. VanderZee KI, Sanderman R, Heyink JW, Haes H. Psychometric qualities of the rand 36-item health survey 1.0: a multidimensional measure of general health status. Int J Behav Med. 1996;3(2):104122. doi:10.1207/s15327558ijbm0302_2

46. Weinberger M, Samsa GP, Schmader K, Greenberg SM, Carr DB, Wildman DS. Comparing proxy and patients' perceptions of patients' functional status: results from an outpatient geriatric clinic. $\mathrm{J} \mathrm{Am}$ Geriatr Soc. 1992;40(6):585-588. doi:10.1111/j.1532-5415.1992. tb02107.x

47. Lutomski JE, Baars MAE, Schalk BWM, et al. The development of the Older Persons and Informal Caregivers Survey Minimum DataSet (TOPICS-MDS): a large-scale data sharing initiative. PLoS One. 2013;8(12):6-13. doi:10.1371/journal.pone.0081673

48. Krabbe PFM, Stouthard MEA, Essink-Bot ML, Bonsel GJ. The effect of adding a cognitive dimension to the EuroQol multiattribute healthstatus classification system. J Clin Epidemiol. 1999;52(4):293-301. doi:10.1016/S0895-4356(98)00163-2

49. Brooks R. EuroQol: the current state of play. Health Policy (New York). 1996;37(1):53-72. doi:10.1016/0168-8510(96)00822-6

50. D'Agostino RBD. Propensity score methods for bias reduction in the comparison of a treatment to a non-randomized control group. Stat Med. 1998;17:2265-2281. doi:10.1002/(ISSN)1097-0258

51. Salisbury C, Man MS, Bower P, et al. Management of multimorbidity using a patient-centred care model: a pragmatic cluster-randomised trial of the 3D approach. Lancet. 2018;392(10141):41-50. doi:10.1016/S0140-6736(18)31308-4

52. Marcus-varwijk AE, Peters LL, Visscher TLSS, Smits CHMM, Ranchor AV, Slaets JPJJ. Impact of a nurse- led health promotion intervention in an aging population : results from a quasi-experimental study on the "community health consultation offices for seniors". $J$ Aging Health. 2018. doi:10.1177/0898264318804946

53. Aaron M, Nelson BW, Kaltsas E, Brown RW, Thomas LJ, Patel MR. Impact of goal setting and goal attainment methods on asthma outcomes: findings from an asthma self-management intervention for African American Women. Heal Educ Behav. 2017;44(1):103-112. doi:10.1177/1090198116637858

54. Dye CJ, Williams JE, Evatt JH. Activating patients for sustained chronic disease self-management: thinking beyond clinical outcomes. J Prim Care Community Health. 2016;7(2):107-112. doi:10.1177/ 2150131915626562

55. Michie S, Ashford S, Sniehotta FF, Dombrowski SU, Bishop A, French DP. A refined taxonomy of behaviour change techniques to help people change their physical activity and healthy eating behaviours: the CALO-RE taxonomy. Psychol Heal. 2011;26(11):14791498. doi:10.1080/08870446.2010.540664

56. Austin P. An introduction to propensity score methods for reducing the effects of confounding in observational studies. Multivar Behav Res. 2011;46:399-424. doi:10.1080/00273171.2011.568786

57. Zwarenstein M, Treweek S, Gagnier JJ, et al. Improving the reporting of pragmatic trials: an extension of the CONSORT statement. $\mathrm{Br}$ Med J. 2008;337:a2390. doi:10.1136/bmj.a2390

58. Bhattacharyya O, Reeves S, Zwarenstein M. What is implementation? Res Soc Work Pract. 2009;19(5):491-502. Available from: http://searchcrm.techtarget.com/definition/imple mentation. doi:10.117/1049731509335528

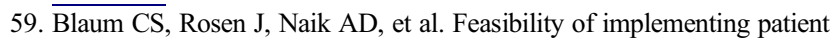
priorities care for older adults with multiple chronic conditions. J Am Geriatr Soc. 2018;66(10):2009-2016. doi:10.1111/jgs.15465

60. Söderlund LL, Madson MB, Rubak S, Nilsen P. A systematic review of motivational interviewing training for general health care practitioners. Patient Educ Couns. 2011;84(1):16-26. doi:10.1016/j. pec. 2010.06 .025

61. Miller WR, Rollnick S. The effectiveness and ineffectiveness of complex behavioral interventions: impact of treatment fidelity. Contemp Clin Trials. 2014;37(2):234-241. doi:10.1016/j.cct.2014.01.005

62. Uittenbroek RJ, Kremer HPH, Spoorenberg SLW, Reijneveld SA, Wynia K. Integrated care for older adults improves perceived quality of care: results of a randomized controlled trial of embrace. $J$ Gen Intern Med. 2017;32(5):516-523. doi:10.1007/s11606-016-3742-y
Clinical Interventions in Aging

\section{Publish your work in this journal}

Clinical Interventions in Aging is an international, peer-reviewed journal focusing on evidence-based reports on the value or lack thereof of treatments intended to prevent or delay the onset of maladaptive correlates of aging in human beings. This journal is indexed on PubMed Central, MedLine, CAS, Scopus and the Elsevier
Bibliographic databases. The manuscript management system is completely online and includes a very quick and fair peer-review system, which is all easy to use. Visit http://www.dovepress.com/ testimonials.php to read real quotes from published authors. 